
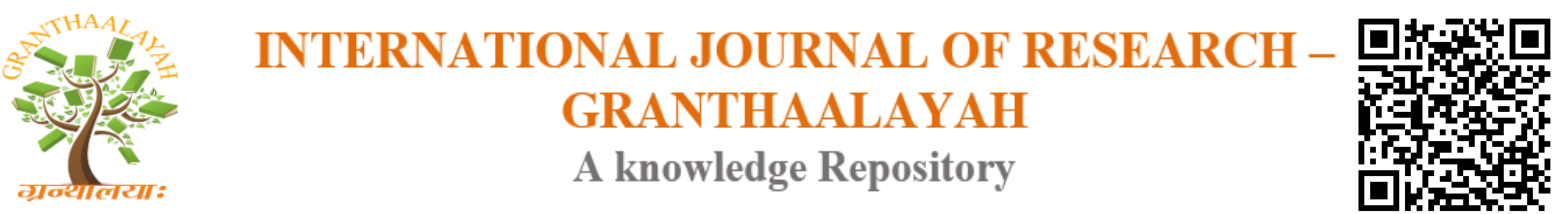

Science

\title{
HUMAN IMMUNO DEFICIENCY VIRUS AND TUBERCULOSIS COINFECTION AMONG PATIENTS ATTENDING HOLLEY MEMORIAL HOSPITAL OCHADAMU, OFU LOCAL GOVERNMENT AREA, KOGI STATE
}

\author{
Abraham-O. J. ${ }^{* 1,7}$, Nwobodo, H. A. ${ }^{2}$, Ngwu, B.A.F. ${ }^{3}$, Onwuatuegwu, J.T.C. ${ }^{4}$, Nwaogwugwu, \\ A. B. ${ }^{5}$, Adelowo, A. E. ${ }^{5}$, Adegbite, A. ${ }^{5}$, Chock, J.J. ${ }^{6}$, Ogbonna, O.Q. ${ }^{1}$ \\ ${ }^{1}$ Department of Science Laboratory Technology, Federal Polytechnic, Idah, Kogi State, Nigeria \\ ${ }^{2}$ Department of Microbiology, ESUT Teaching Hospital, Enugu \\ ${ }^{3}$ Department of Microbiology, Ebonyi State University, Abakaliki \\ ${ }^{4}$ Tansian University, Umunya, Anambra State \\ ${ }^{5}$ Laboratory Unit, Holley Memorial Hospital Ochadamu, Ofu LGA, Kogi State \\ ${ }^{6}$ Department of Medical Microbiology, Kaduna State University Teaching Hospital, Kaduna \\ ${ }^{7}$ Department of Microbiology, Kaduna State University, Kaduna
}

\begin{abstract}
Tuberculosis and human Immuno-deficiency virus co-epidemics remain a major public health challenge particularly in resource limited settings. This study determined the prevalence of HIV co-infection among TB patients and the risk factors among patients attending Holly memorial Hospital Ochadamu, Ofu L.G.A., Kogi State, Nigeria. Two hundred (200) patients participated in the research, out of which one hundred and seventy three (173) were already confirmed to be HIV positive. Sputum samples were collected by experts into sample bottles aseptically for Acid fast Bacilli test for Mycobacterium tuberculosis; while blood samples were collected by trained nurses from the same candidates by venepuncture into anticoagulated bottles for HIV screening to re- confirm their status. Questionnaires were also administered to obtain some important demographic data. Sputum smear microscopy was carried out to test for Acid Fast Bacilli. Rapid haemagglutination assay was carried out to re-confirm the HIV status of the patients. Results showed that Twenty seven (27) patients signifying $13.5 \%$ were TB/HIV co-infected. There was significant $(\mathrm{p}<0.05)$ relationship between TB and HIV status of the patients and clinical symptoms (dry cough, cough with sputum, weight loss and fever). There is need to study Immuno-haematological indices (CD4 count, Full Blood Count and ESR) routinely to monitor TB and HIV patients on regular basis in order to reduce morbidity and mortality associated with the diseases.
\end{abstract}

Keywords: Tuberculosis; Human Immunodeficiency virus; Co-infection; Prevalenc; Hospital. 
Cite This Article: Abraham-O. J., Nwobodo, H. A., Ngwu, B.A.F., Onwuatuegwu, J.T.C., Nwaogwugwu, A. B., Adelowo, A. E., Adegbite, A., Chock, J.J., and Ogbonna, O.Q.. (2017). "HUMAN IMMUNO DEFICIENCY VIRUS AND TUBERCULOSIS COINFECTION AMONG PATIENTS ATTENDING HOLLEY MEMORIAL HOSPITAL OCHADAMU, OFU LOCAL GOVERNMENT AREA, KOGI STATE." International Journal of Research - Granthaalayah, 5(8), 55-62. https://doi.org/10.29121/granthaalayah.v5.i8.2017.2182.

\section{Introduction}

Tuberculosis (TB) and human immunodeficiency virus (HIV) co-epidemics remain a major public health challenge, particularly in resource limited settings (Tadess et al., 2013). There were an estimated 1.1 million TB/HIV co-Infected patients worldwide in 2011, 79\% of those cases were in Africa (WHO, 2012). There has been a strong link between tuberculosis (TB) and HIV, as they are both capable of disarming the host's immune responses. TB is the most common opportunistic disease which kills those infected with HIV (Modjarrad and Vermund., 2010). HIV co-infection also increases the risk of latent TB reactivation by 20 -fold, and is the most powerful known risk factor for progression of Mycobacterium tuberculosis infection to active disease (Getahum et al., 2010; Kwan and Ernst, 2011). In Nigeria, the majority of TB infections are caused by $M$. tuberculosis followed by $M$. africanum and M. bovis, and most importantly, the burden of the disease is the highest in Africa. Nigeria ranks top in Africa with respect to the burden of both TB and HIV infections. In 2007, the estimated proportion of TB cases that were coinfected with HIV was $27 \%$ (Dim, 2012).

To improve the diagnostic and intervention outcomes for TB/HIV co-Infection patients, world health organization (WHO) developed a framework of strategic collaborative activities to be performed as parts of health sector response to control co-epidemic (WHO, 2004). .

Furthermore, the global effort at controlling the disease through the Stop TB initiative has been seriously challenged by the human immunodeficiency virus (HIV) pandemic in developing countries. This is because, TB is associated with HIV infection; HIV-positive individuals are about 20 to 37 times more likely to develop TB when compared to HIV-negative individuals. Likewise, a TB patient who is coinfected with HIV (TB/HIV) is more likely to die, and when sputum positive (ss+), is more likely to transmit the infection (Dim, 2012).

Knowledge about HIV co-infection status among TB patients might help understand the spread of the dual infection and to monitor the performances of TB and HIV control activities (WHO, 2012).

This study determined the prevalence and risk factors of HIV co-Infection among Tuberculosis patients attending Holley Memorial Hospital Ochadamu, Ofu Local Government Area, Kogi State. 


\section{Materials and Methods}

\subsection{Study Area and Population}

This study was carried out at Holley Memorial Hospital, Ochadamu, Ofu L.G.A, Kogi state. Kogi State is located in the central belt of Nigeria on Latitude $7^{\circ} 48^{\prime} 0^{\prime \prime} \mathrm{N}$ and Longitude $6^{\circ} 44^{\prime}$ 0 "E. The people have a mixed culture with farming as their major occupation. The hospital was founded as a Non-Governmental Organization (NGO) in 1950 by the Qua Iboe fellowship, a local Nigerian church in response to the needs of those suffering from leprosy in Nigeria. HMH is recognized by the Nigerian Government as a place of excellence in the treatment of Leprosy and Tuberculosis. The Department is run in partnership with the Leprosy mission international. Today however, the hospital has grown to be a large general hospital providing specialist services in surgery, maternity and obstetrics, orthopaedics, ophthalmics and caring for an increasing number of people suffering from TB and HIV/AIDS. A large out patients Department cares for the growing local population.

\subsection{Inclusion/Exclusion Criteria}

The inclusion criteria for the study subjects were HIV infected patients receiving antiretroviral treatment at the Holley Memorial Hospital Ochadamu during the period of the study (January to October 2015) who gave informed consent to participate in the study. The population groups covered during the study was adult men and women attending antiretroviral control (ARC) in the hospital. It is pertinent to mention that those healthy adult are the reproductive group and are therefore a good proxy for the general population in the determination of the prevalence of TB, HIV and TB/HIV coinfection. Patients that were too sick and unable to communicate were excluded from the study.

\subsection{Sample Collection}

Blood sample was collected from patients and transferred into an ethylene diamine-tetraacetric acid (EDTA) for HIV test, while sputum samples were obtained from each patient, thus each patient produced two sputum sample within an hour interval.

\subsection{HIV Test}

HIV test was carried out using rapid test kit Determine ${ }^{(\mathrm{R})}$ (manufactured by Alere, San Dio. Callifonia) Start pack was used as confirmatory test.

Samples are collected from patients through venepuncture. The blood sample is centrifuged at $1500 \mathrm{rpm}$ for 5 minutes to prepare the serum. HIV screening was carried out according to manufacturers' manual.

\subsection{AFB Test}

TB diagnosis was made based on the findings of acid fast bacilli by Zielneelson (ZN) staining. Sputum specimen we decontaminated by modified Petroff's methods using sodium hydroxide 
$(\mathrm{NaOH})$ and then concentrated by centrifugation at 3000rpm for 15 minutes. After centrifugation it was examined by microscopy.

\subsection{Statistical Analysis}

Complete questionnaire were coded by numbers and entered in a computer software excel crosschecking and data cleaning was done the data was then transferred to statistical package for social science version 16 (Spss Inc Chicago, USA) and graph pad prism 5 for analysis. Chisquare test was used to test for differences in proportions. Student test was used to test for differences in means between two or more groups. All statistical test were considered significant if the two sided P-value (p) was $<0.05$

\section{Results}

\section{Age Distribution of TB/HIV Co-infected Patients Attending Holley Memorial Hospital Ochadamu}

Age distribution of TB/HIV co-infected patients attending Holley memorial hospital showed that out the 200 patients, 27 (13.5\%) patients are TB/HIV co-infected (Table 1). Age group 21-years recorded coinfection rate of $4-5 \%$.

Table 1: Age distribution of TB/HIV Co-infected Patients Attending Holley Memorial Hospital Ochadamu

\begin{tabular}{|l|l|c|c|l|}
\hline Age & No of respondents & No positive & & Prevalence \% \\
\hline $0-10$ & 12 & 0 & 0.0 \\
\hline $11-20$ & 22 & 4 & 2.0 \\
\hline $21-30$ & 51 & 8 & 4.0 \\
\hline $31-40$ & 67 & 10 & 5.0 \\
\hline $41-50$ & 27 & 2 & 1.0 \\
\hline $51-60$ & 13 & 1 & 0.5 \\
\hline $61-70$ & 4 & 1 & 0.5 \\
\hline $71-80$ & 4 & 1 & 0.5 \\
\hline $81-90$ & 00 & 00 & 0.0 \\
\hline $91-100$ & 00 & 00 & 0.0 \\
\hline Total & 200 & 27 & 13.5 \\
\hline
\end{tabular}

$\mathrm{X}^{2}$ cal $=7 ; \alpha=0.05 ; \mathrm{P}=0.001$

\section{Gender Distribution of HIV/TB Co-infected Patients Attending Holley Memorial Hospital Ochadamu}

Gender distributions of TB/HIV coinfected patients showed that $16(8.0 \%)$ male are TB/HIV coinfected while 11(5.5\%) female are TB/HIV coinfected (Table 2). 
Table 2: Gender Distribution of HIV/TB coinfected patients attending Holley memorial hospital ochadamu

\begin{tabular}{|l|l|l|l|l|}
\hline Gender & No of respondents & No positive & No negative & Prevalence \% \\
\hline Male & 85 & 16 & 69 & 8.0 \\
\hline Female & 115 & 11 & 104 & 5.5 \\
\hline Total & 200 & 27 & 173 & 13.5 \\
\hline
\end{tabular}

$\mathrm{X}^{2}$ tab $=1.005 ; \mathrm{P}=0.00001 ; \alpha=0.05$.

\section{Distribution of TB/HIV Coinfection among Patients Attending Holley Memorial Hospital Based on their Marital Status}

On the basis of marital status, $14(18.2 \%)$ were single, $12(10.3 \%)$ were married, $1(3.3 \%)$ divorced (Table 3).

Table 3: Distribution of TB/HIV coinfection among patients attending Holley Memorial Hospital based on their marital status

\begin{tabular}{|l|l|l|l|l|}
\hline Marital status & No of respondents & No positive & No negative & Prevalence \% \\
\hline Single & 77 & 14 & 63 & 18.2 \\
\hline Married & 117 & 12 & 105 & 10.3 \\
\hline Widow/widower & 1 & 0 & 1 & 0.0 \\
\hline Divorced & 3 & 1 & 2 & 3.3 \\
\hline Separated & 2 & 0 & 2 & 0.0 \\
\hline Total & 200 & 27 & 173 & 13.5 \\
\hline
\end{tabular}

$\mathbf{X}^{2}=4.05 ; \mathrm{p}=0.0001 ; \alpha=0.005$.

\section{Educational Status of TB/HIV Co-infected Persons Attending Holley Memorial Hospital Ochadamu}

The Educational status of respondents shows that out of 15 primary school certificate holders 1 $(6.6 \%)$ was coinfected; 36 were up to secondary school level with $8(22.2 \%)$ coinfected;, 21 had National Diploma certificate with $1(5.0 \%)$ positive; 61 had NCE certificate with $8(13.1 \%)$ positive; 54 were university graduate with 7 (13.0\%) positive, while 13 had no formal education with $2(15.4 \%)$ positive (Table 4$)$.

Table 4: Educational status of HIV/TB coinfected patients attending Holley memorial hospital

\begin{tabular}{|l|l|l|l|l|}
\hline Educ. Status & $\begin{array}{l}\text { No } \\
\text { respondents }\end{array}$ & No positive & No negative & Prevalence \% \\
\hline Primary school & 15 & 1 & 14 & 6.6 \\
\hline Secondary school & 36 & 8 & 28 & 22.2 \\
\hline ND & 21 & 1 & 20 & 5.0 \\
\hline NCE & 61 & 8 & 53 & 13.1 \\
\hline Uni/graduate & 54 & 7 & 47 & 13.0 \\
\hline No formal education & 13 & 2 & 11 & 15.4 \\
\hline Total & 200 & 27 & 173 & 13.5 \\
\hline
\end{tabular}

$\mathrm{X}^{2}$ tab $=6.05 ; \mathrm{P}=0.0001 ; \alpha=0.05$. 


\section{Occupational Distribution of TB/HIV Coinfected Patients Attending Holley Memorial Hospital Ochadamu}

On the basis of occupational status of patients showed that $10(17.5 \%)$ were businessmen/women; 6 (8.2\%) were public servants; 1 (9.1\%) were farmers; 1 (33.3\%) were private business owners, while $9(16.1 \%)$ were dependent (Table 5).

Table 5: Occupational distribution among TB/HIV coinfected patients attending holley memorial hospital ochadamu.

\begin{tabular}{|l|l|l|l|l|}
\hline Occupation & No of respondents & No positive & No negative & Prevalence \% \\
\hline Businessmen/women & 57 & 10 & 47 & 17.5 \\
\hline Public service & 73 & 6 & 67 & 3.0 \\
\hline Farmer & 11 & 1 & 60 & 9.1 \\
\hline Private & 3 & 1 & 2 & 0.5 \\
\hline Dependent & 56 & 9 & 47 & 16.1 \\
\hline Total & 200 & 27 & 173 & 13.5 \\
\hline
\end{tabular}

$\mathrm{X}^{2}$ tab $=4.05 ; \mathrm{P}=0.0001 ; \alpha=0.05$.

\section{Clinical Signs of TB/HIV Coinfected Patents Attending Holley Memorial Hospital Ochadamu}

Clinical sign of respondents attending Holley Memorial Hospital Ochadamu showed that 23 (85.2\%) had cough with sputum; 24 (88.9\%) had dry cough; 17 (63.0\%) had fever; 9 (33.3\%) had loss of weight; $3(11.1 \%)$ had tiredness, but of the 27 patients with loss of appetite none was HIV/TB coinfected (Table 6). Other symptoms of HIV or TB were not displayed by the patients.

Table 6: Clinical Sign among TB/HIV Coinfected Patents Attending Holley Memorial Hospital Ochadamu

\begin{tabular}{|l|l|l|l|l|}
\hline Clinical signs & No of respondents & No positive & No negative & Prevalence \% \\
\hline Cough with sputum & 27 & 23 & 4 & 85.2 \\
\hline Drug cough & 27 & 24 & 3 & 88.9 \\
\hline Fever & 27 & 17 & 10 & 63.0 \\
\hline Weight loss & 27 & 9 & 18 & 33.3 \\
\hline Tiredness & 27 & 3 & 24 & 11.1 \\
\hline Loss of Appetite & 27 & 0 & 27 & 0 \\
\hline Chest pain & 0 & 0 & 0 & 0 \\
\hline Short breath & 0 & 0 & 0 & 0 \\
\hline Swelling of the neck & 0 & 0 & 0 & 0 \\
\hline Pneumonia & 0 & 0 & 0 & 0 \\
\hline Diarhoea & 0 & 0 & 0 & 0 \\
\hline Fungal infection of the skin & 0 & 0 & 0 & 0 \\
\hline Night sweat & 0 & 0 & 0 & 0 \\
\hline Total & 162 & 76 & 86 & 46.91 \\
\hline
\end{tabular}




\section{Discussion}

This study revealed a mean TB/HIV co-infection of $13.5 \%$ (Table 1 ). This is does not agree with the higher prevalence of $34.5 \%$ mean coinfection reported for Enugu State in a similar study carried out by Dim (2012). At the community level, TB/ HIV transmission is more likely, and can substantially increase health-care costs, particularly for hospitalization to treat opportunistic infections and decrease productivity (Nachega et al., 2015). From table 6, there was significant relationship $(\mathrm{P}<0.05)$ between HIV/TB coinfection with clinical signs such as coughing with sputum and dry cough. As HIV progresses immunity declines, patients become more susceptible to infections such as TB, pneumonia, recurrent fungal infections of the skin and oropharynx. These infections can occur at any stage of progression of HIV infection and immune suppression. Some patients may develop constitutional symptoms (unexplained fever and weight loss) previously known as AIDS-related complex (ARC) or specific HIV related diseases occurring predominantly with severe immune suppression such as certain opportunistic infections (e.g. cryptococcal meningitis) and certain tumours (e.g. Kaposi sarcoma). At this late stage, it is sometimes known as "full-blown AIDS" (Deschamps et al., 2000; Corbette et al., 2003).

HIV increases susceptibility to infection with $M$. tuberculosis infection leading to TB disease. The risk increases with increasing immunosuppression. HIV increases not only the risk but also the rate of progression of recent or latent $M$. tuberculosis infection to diseases (Corbette et al., 2003).

The burden of tuberculosis (TB) in Nigeria is high, and unfortunately, the data from the TB programme of the States' ministries of health are usually unpublished, which possibly contribute to the prevailing ignorance and poor attitude of Nigerians to the disease (Dim and Dim, 2013). In this study, TB/HIV coinfection was higher from the ages of $10-40$ (Table 1). The prevalence was also higher in males than in females (Table 2). This does not agree with the observation of Dim and Dim (2013) in a similar study in Enugu State, who reported that the number of female TB cases was higher than males within the 0-14 age group only. The annual number of all TB cases showed a rising trend. The study therefore recommend that clinical symptoms and immunohaematogical indices (CD4 count, FBC and ESR) must be performed routinely to monitor TB and HIV patients on regular basis in order to reduce morbidity and mortality associated with the diseases. Future research should be conducted to identify strains of MTB in order to help prevent MDR cases among HIV patients.

\section{Conclusion}

TB/HIV coinfection was $13.5 \%$ among the patients as determined by sputum smear microscopy alone. There were significant relationships between TB and HIV status of the respondents and clinical symptoms (dry cough couogh with sputum, weight loss and fever). Female had more prevalence of TB/ HIV coinfected patients than males The highest rate of infection for both $M$. tuberculosis and HIV was among the age range of 25-69years.

The findings of this study were very important and could be used in the monitoring and management of TB and HIV coinfection. 


\section{References}

[1] Corbette, E.L., Watt C.J., Walker, N., Maher. D., Williams, B.G (2003). The growing burden of tuberculosis. Global trends and interaction with HIV epidemic. Arch. Int. med. 163:1009-1021.

[2] Deschamps, M., Fitzgerald, D., Pape. J and Johnson, W. (2000), HIV infection in Haiti: Natural History and Disease Progression. AIDS, 14(16), 2515-252).

[3] Dim C C. (2012): Declining uptake of HIV testing among tuberculosis patients in Enugu state of Nigeria: The need for a reappraisal of strategy. Niger J Clin Pract. 15(2):206 - 209.

[4] Dim, C. C. and Dim, N. R. (2013): Trends of tuberculosis prevalence and treatment outcome in an under-resourced setting: The case of Enugu state, South East Nigeria. Niger Med J. 54(6): 392397

[5] Getahun, H., Gunnebery C, Granich R and Nunn P (2010). HIV. Infection Associated Tuberculosis: the Epidemiology and the response Clinical Infection. Disease 50 (3): 201-207.

[6] Kwan C K and Enrst J.D. (2011). HIV and tuberculosis: a deadly human syndemic. Clinical. Microbial. Review. 24.(2): 351-376.

[7] Modjarrad K. and Vermund, S.H. (2010). Effect of treating coinfection on HIV-1 viral load: a systematic review Lancet Infect. Dis 10: 455-463.

[8] Nachega, J. B., Uthman, O. A., Peltzer, K., Richardson, L. A., Mills, E. J., Amekudzi, K. and Ouédraogo, A. (2015): Association between antiretroviral therapy adherence and employment status: systematic review and meta-analysis. Bulletin of the World Health Organization.93:29-41. doi: http://dx.doi.org/10.2471/BLT.14.138149

[9] WHO (2012) Global tuberculosis control Geneva.

[10] WHO (2004), Interim policy on collaborative TB/HIV activities, Geneva.

*Corresponding author.

E-mail address: josephoyiguh@ yahoo.com 